\title{
Effects of Levetiracetam Compared to Valproate on Cognitive Functions of Patients with Epilepsy
}

This article was published in the following Dove Press journal:

Neuropsychiatric Disease and Treatment

\author{
Ramy M El Sabaa' \\ Emad $\mathrm{Hamdi}^{2,3}$ \\ Nermin Aly Hamdy ${ }^{4}$ \\ Hatem A Sarhan ${ }^{5}$ \\ 'Clinical Pharmacy Department, Faculty \\ of Pharmacy, Deraya University, Minia, \\ Egypt; ${ }^{2}$ Deraya University President, \\ Minia, Egypt; ${ }^{3}$ Psychiatry Department, \\ Faculty of Medicine, Cairo University, \\ Cairo, Egypt; ${ }^{4}$ Neurology Department, \\ Faculty of Medicine, Minia University, \\ Minia, Egypt; ${ }^{5}$ Pharmaceutics \\ Department, Faculty of Pharmacy, Minia \\ University, Minia, Egypt
}

Objective: This study compared the effect of levetiracetam (LEV) as monotherapy to sodium valproate (VPA) as monotherapy on cognitive functions in patients with epilepsy.

Methods: This was a comparative prospective study on 50 patients with newly diagnosed epilepsy started on antiseizure medications. Patients were selected from the neurologyoutpatient clinics at Minia University Hospital, Minia, Egypt. They were divided into two groups: group treated with LEV and group treated with VPA. All patients were subjected to cognitive function assessment using reaction-time tests, trail-making tests, and Wisconsin card-sorting test before treatment and 3 months after treatment.

Results: Both groups of patients showed reduction in seizure frequency. However, patients on LEV showed significant improvement in measured cognitive functions 3 months after starting treatment, while patients in the VPA group showed significant impairment in measured cognitive functions 3 months after starting treatment.

Conclusion: Both groups of patients showed reduction in seizure frequency. However, patients on LEV showed significant improvement in measured cognitive functions 3 months after starting treatment, while patients in the VPA group showed significant impairment in measured cognitive functions 3 months after starting treatment.

Keywords: cognitive function, epilepsy, levetiracetam, valproate, monotherapy

\section{Introduction}

Epilepsy is the most common neurological disease. According to the World Health Organization(WHO), 50 million people are suffering from epilepsy. ${ }^{1}$ Antiseizure medications are the backbone of epilepsy management for patients of all ages. The target of treating epileptic patients is to control seizures completely without causing unwanted side effects. ${ }^{2}$ Antiseizure medications are known to affect the cognitive abilities in epileptic patients. Slowing of mental function and decreased concentration, awareness, and psychomotor speed are the main adverse cognitive events related to antiseizure medications. ${ }^{3}$ Antiseizure medications affect cognition by reducing neuron excitability or enhancing inhibitory neurotransmission. ${ }^{4}$ The presence of cognitive side effects caused by antiseizure medications is a major concern for patients with epilepsy taking medication. ${ }^{5}$

Levetiracetam (LEV), one of the most prescribed antiseizure medications, is widely used in many forms of treatment for epilepsy. It is used in the treatment of focal-onset, myoclonic, and generalized tonic-clonic seizures as monotherapy and add-on therapy. ${ }^{6}$ LEVshows good tolerability and a positive impact on neuropsychological tests. Many studies have show that no significant changes are observed in cognitive function with $\mathrm{LEV}^{7}$ Sodium valproate (VPA) is also a broad-spectrum
Correspondence: Ramy M El Sabaa

Clinical Pharmacy Department, Faculty of Pharmacy, Deraya University, Minia, New Minia 61768, Egypt

Tel +20-10-0635-0788

Email dr.ramypharma@gmail.com
Neuropsychiatric Disease and Treatment 2020:16 1945-1953

1945

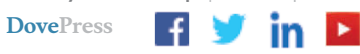

http://doi.org/10.2147/NDTS256117 
antiseizure medication used not only for epilepsy but also for other neuropsychiatric disorders, such as bipolar disease and migraine. It has been associated with some cognitive impairment in bipolar disease. ${ }^{8}$ There is limited evidence on the comparative effects of antiseizure medications on cognitive functions, while most recent studies have focused on comparisons of efficacy and tolerability of antiseizure medications. ${ }^{9,10}$ This study was performed to compare the effects of two well-known antiseizure medications LEV and VPA as monotherapy on cognitive functions of patients with epilepsy.

\section{Methods}

\section{Subjects}

This was a comparative prospective open study undertaken at neurology-outpatient clinics of Minia University Hospital, Minia, Egypt from January 2018 to March 2019. Fifty patients with newly diagnosed epilepsy were included after obtaining written informed consent. The study was conducted in accordance with the Declaration of Helsinki and approved by the Commission on the Ethics of Scientific Research, Faculty of Pharmacy, Minia University.

Subjects were divided into two groups of 25 each. The first group was treated with LEV, and the second group treated with VPA, both as monotherapy, based on physician discretion. Inclusion criteria were newly diagnosed focal and generalized epilepsy patients according to classification of epileptic seizures proposed by the International League Against Epilepsy, age $\geq 16$ years, not on antiseizure medication, having been prescribed monotherapy with one of the two antiseizure medications (LEV and VPA).

\section{Exclusion Criteria}

Patients with any progressive central nervous system disease, extreme cardiovascular abnormality, underlying malignancy and hypersensitivity to any of the medications tested, untreated serious concurrent disease, irregular liver and kidney function, pregnant and lactating, and a history of drug-related seizures, alcohol, or acute medical or psychiatric conditions were excluded from the analysis.

\section{Procedure}

A detailed history and general physical and neurological examinations were performed for each patient. Seizures were classified according to the International League Against Epilepsy 2017 classification of seizures. ${ }^{11}$
Electroencephalography was done for confirmation of seizure type. Dose ranges at the start of the study were 1,000-2,000 mg/day for LEV and 1,000-1,500 mg/day for VPA. Follow up duration was 3 months.

\section{Cognitive Function Tests}

Assessment of cognitive function was based on the simple reaction-time test, choice reaction-time test, trail-making tests $\mathrm{A}$ and $\mathrm{B}$, and Wisconsin card-sorting test (WCST). Patients were evaluated before treatment and 3 months after treatment.

\section{Simple and Choice Reaction-Time Tests}

The basic idea is that response times represent the time it takes to perceive a stimulus, acquire memory information, and activate a muscle response. Therefore, response times can be used to find out how long basic thought processes take. The test score is the reaction time in milliseconds. For the simple reaction-time test, there is only one stimulus, and the subject needs to respond each time it occurs. In this task, the participant needs to wait until they see a black cross on the white square. When that happens, they press the space bar. As such, there is one stimulus (black cross) and one response (pressing the space bar). For the choice reaction-time test, there are several stimuli and each stimulus needs a different response. In this task, the participant needs to wait until they see a black cross on one of the four white squares (eg, there are four blackcross positions, which counts as four different stimuli). When that happens, they will press on the corresponding key $(\mathrm{z}, \mathrm{x}, \mathrm{c}$, or $\mathrm{b})$. As such, there are four stimulusresponse associations. ${ }^{12}$

\section{Trail-Making Tests}

These are visual-focus and task-changing neuropsychological tests. They can provide data on the speed of visual search, scanning, processing speed, mental flexibility, and executive functioning. Tasks require a subject to attach a series of consecutive goals on a sheet of paper or computer screen. The score of the test is the number of seconds needed to complete the mission. ${ }^{13}$ There are two parts to the test:

Trail-making part A : all numbers $(1,2,3$, etc) are goals and must be linked in sequential order by the subject. This method is specifically used to examine the speed of cognitive processing 
Trail-making part $\mathrm{B}$ : the topic alternates between numbers and letters (1, A, 2, B, etc). This method is used to evaluate the functioning of the executive.

\section{Wisconsin Card-Sorting Test}

This is a test of attention, concentration, and problemsolving. In the WCST, cards must be graded according to different criteria by individuals. Every card is categorized in four ways, and the only input is whether the classification is right or not. Cards can be categorized by the color of their symbols, the form of the symbols, or the number of symbols on each card. The classification rule changes every ten cards, and this ensures that once the participant has decided the rule, one or more mistakes will be made by the participant when the rule changes. The task measures how well people can adapt to the changing rules. The test score is the number of correct cards and the number of perserverative and nonperserverative errors. ${ }^{14}$

\section{Statistical Analysis}

Results are expressed as means \pm SE. Differences among groups were statistically analyzed by one-way ANOVA, followed by Tukey's HSD post hoc test for multiple compar- isons for all tests $P<0.05$ was considered statistically significant. All data analyses were performed using GraphPad Prism 7.

\section{Results}

\section{Demographic Profile of Patients}

Fifty patients who fulfilled the eligibility criteria were enrolled, as shown in Figure 1. Demographic data are shown in Table 1. No significant differences were observed between the groups.

\section{Seizure Frequency Between LEV Group and VPA Group}

Patients treated with LEV reported lower seizure frequency at 3 months after treatment (mean reduction from pretreatment was $6.76 \pm 4.4$ to $0.17 \pm 0.49$ at 3 months after treatment). In the VPA group, mean reduction from pretreatment was $6.88 \pm 4.3$ to 0.23 \pm 0.52 at 3 months after treatment. However, this difference was not statistically significant. Both drugs as monotherapy showed similar seizure-frequency reduction (Table 2).

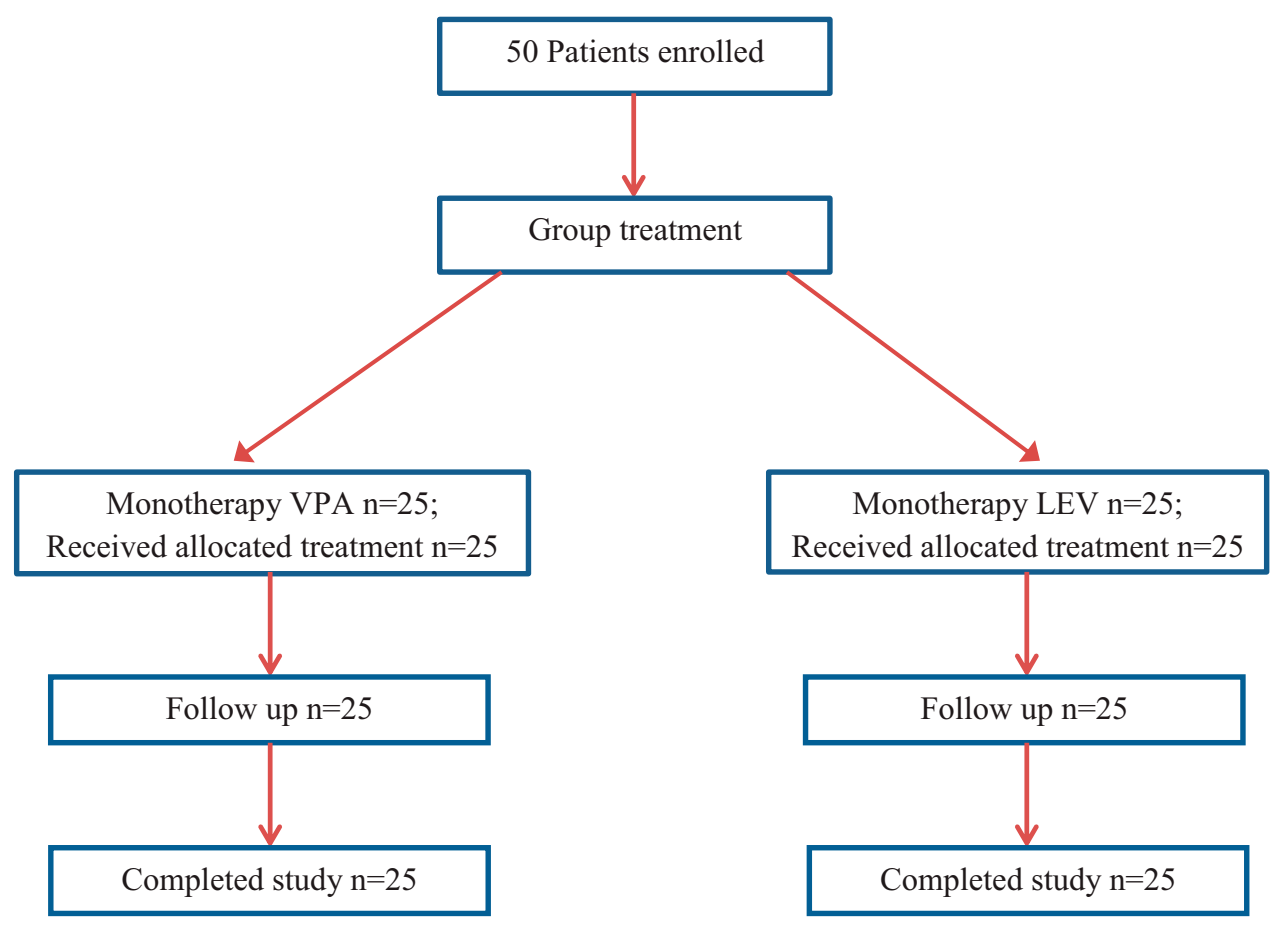

Figure I Flow chart for patient disposition.

Abbreviations: LEV, levetiracetam, VPA, sodium valproate. 
Table I Demographic Profile of Patients of Epilepsy in Both Groups

\begin{tabular}{|c|c|c|c|}
\hline $\begin{array}{l}\text { Demographic } \\
\text { Profile }\end{array}$ & $\begin{array}{l}\text { LEV Group } \\
(n=25)\end{array}$ & $\begin{array}{l}\text { VPA Group } \\
(n=25)\end{array}$ & P-value \\
\hline Age (mean $\pm S D)$ & $39.76 \pm 12.7$ & $38.44 \pm 12.5$ & 0.7 \\
\hline $\begin{array}{l}\text { Sex } \\
\text { Males } \\
\text { Females }\end{array}$ & $\begin{array}{l}13(52.0 \%) \\
12(48.0 \%)\end{array}$ & $\begin{array}{l}16(64.0 \%) \\
9(36.0 \%)\end{array}$ & 0.5 \\
\hline $\begin{array}{c}\text { Educational level } \\
\text { Primary School } \\
\text { Secondary School }\end{array}$ & $\begin{array}{l}9(36.0 \%) \\
16(64.0 \%)\end{array}$ & $\begin{array}{l}8(32.0 \%) \\
17(68.0 \%)\end{array}$ & 0.9 \\
\hline $\begin{array}{l}\text { Types of seizures } \\
\text { Generalized tonic } \\
\text { clonic seizures } \\
\text { Focal Motor seizures }\end{array}$ & $\begin{array}{l}22(88 \%) \\
3(12.0 \%)\end{array}$ & $\begin{array}{l}19(76.0 \%) \\
6(24.0 \%)\end{array}$ & 0.4 \\
\hline
\end{tabular}

Table 2 Comparison of the Seizure Frequency Between LEV Group and VPA Group

\begin{tabular}{|c|c|c|c|}
\hline Seizures/Month & $\begin{array}{l}\text { LEV (Mean } \\
\pm S D)(n=25)\end{array}$ & $\begin{array}{l}\text { VPA (Mean } \\
\pm S D)(n=25)\end{array}$ & P-value \\
\hline Before treatment & $6.76 \pm 4.4$ & $6.88 \pm 4.3$ & 0.9 \\
\hline $\begin{array}{l}\text { One month after } \\
\text { treatment }\end{array}$ & $3.68 \pm 4.0$ & $4.36 \pm 4.2$ & 0.5 \\
\hline $\begin{array}{l}\text { Two months after } \\
\text { treatment }\end{array}$ & $0.95 \pm 1.33$ & $2.16 \pm 3.4$ & 0.1 \\
\hline $\begin{array}{l}\text { Three months } \\
\text { after treatment }\end{array}$ & $0.17 \pm 0.49$ & $0.23 \pm 0.52$ & 0.7 \\
\hline
\end{tabular}

Table 3 Comparison of the Seizure Freedom Between LEV Group and VPA Group

\begin{tabular}{|l|l|l|l|}
\hline $\begin{array}{l}\text { Seizure } \\
\text { Freedom }\end{array}$ & $\begin{array}{l}\text { LEV (Mean } \\
\mathbf{\pm S D})(\mathbf{n = 2 5})\end{array}$ & $\begin{array}{l}\text { VPA (Mean } \\
\mathbf{\pm S D})(\mathbf{n = 2 5})\end{array}$ & P-value \\
\hline $\begin{array}{l}\text { One month after } \\
\text { treatment }\end{array}$ & $5(20 \%)$ & $4(16 \%)$ & 0.9 \\
$\begin{array}{l}\text { Two months after } \\
\text { treatment } \\
\text { Three months } \\
\text { after treatment }\end{array}$ & $14(56 \%)$ & $10(40 \%)$ & 0.5 \\
\hline
\end{tabular}

\section{Seizure Freedom Between LEV Group and VPA Group}

Patients in the LEV group achieved better seizure control than the VPA group: seizure freedom was $80 \%$ at 3 months after treatment for the LEV group and $72 \%$ for the VPA group. However, this difference was not statistically significant (Table 3 ).

\section{Cognitive Function Tests}

Simple Reaction-Time Test

Comparison of simple reaction-time test-score changes between groups revealed there was deterioration in scores in the VPA group compared to scores in the LEV group, which showed improvements in scores. There was a significant difference between groups 3 months after treatment, where means were $592.7 \pm 238.3$ for LEV and 927.1 \pm 322.2 for VPA $(p=0.005)$. A significant improvement was seen from $861.2 \pm 317.8$ at pretreatment to $592.7 \pm 238.3$ at 3 months after treatment in the LEV group $(p=0.03)$. In the VPA group, scores deteriorated from $713.4 \pm 282.2$ at pretreatment to $927.1 \pm 322.2$ at 3 months after treatment, which was not statistically significant ( $p=0.1$ ) (Figure 2 ).

\section{Choice Reaction-Time Test}

Comparison of choice reaction-time test-score changes between groups revealed deterioration in the scores in the VPA group compared to scores in the LEV group, which showed improvements. There was a significant difference between groups 3 months after treatment, with means of $895.5 \pm 238.1$ for LEV and $1501.3 \pm 296.3$ for VPA $(p<0.0001)$, and significant improvement was seen from $1267.5 \pm 327.4$ at pretreatment to $895.5 \pm 238.1$ at 3 months after treatment in the LEV group $(p=0.0003)$. In the VPA group, mean scores deteriorated from 1240.0 \pm 294.6 at pretreatment to $1501.3 \pm 296.3$ at 3 months after

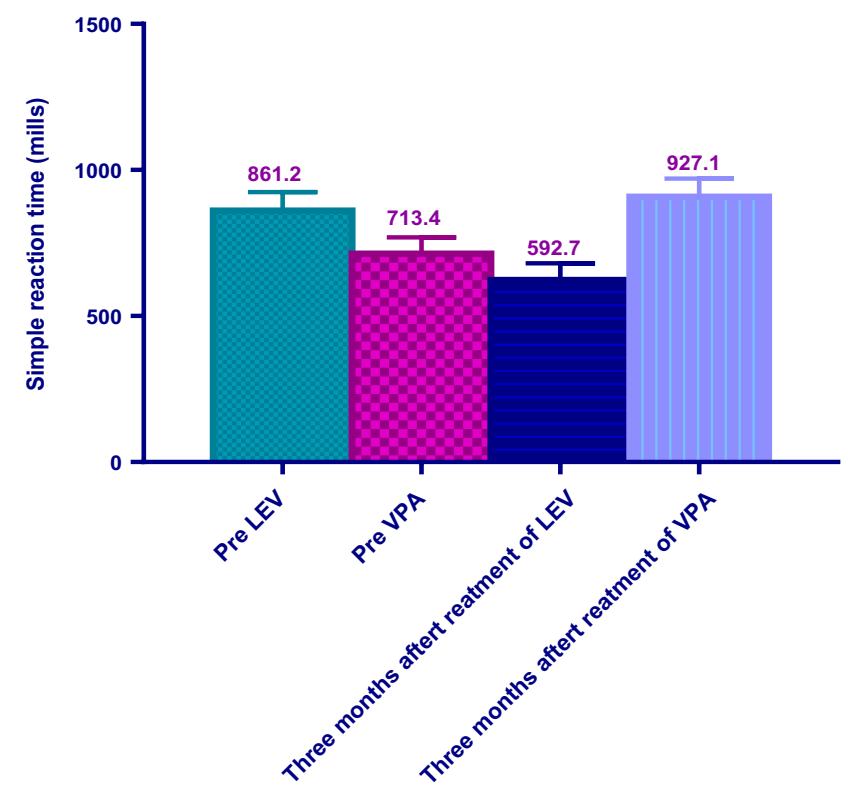

Figure 2 Effect of LEV group and VPA group on simple reaction time. Abbreviations: LEV, levetiracetam, VPA, sodium valproate. 


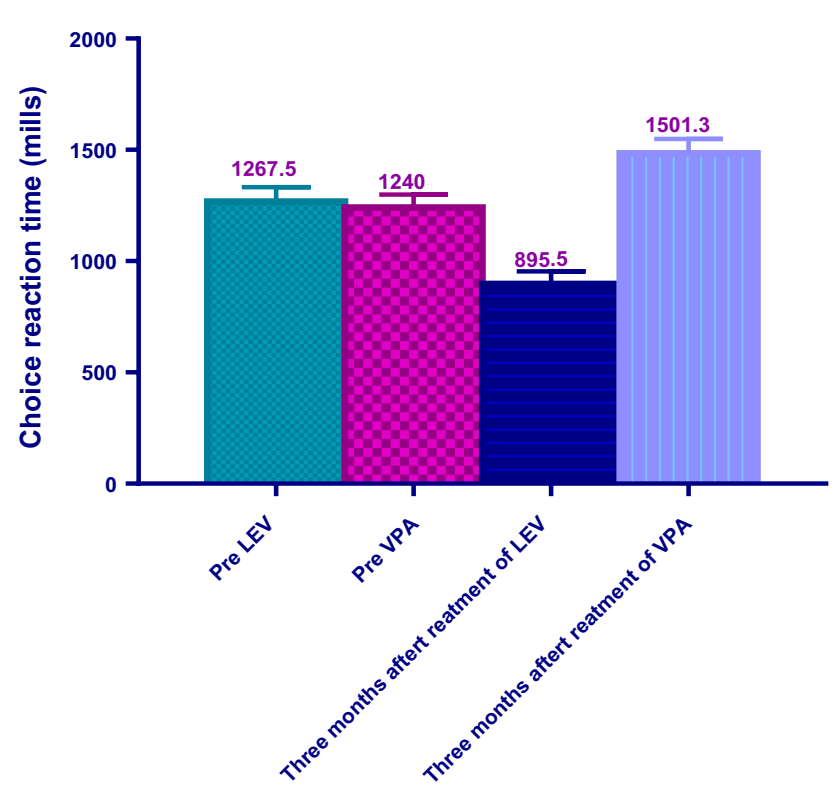

Figure 3 Effect of LEV group and VPA group on choice reaction time. Abbreviations: LEV, levetiracetam, VPA, sodium valproate.

treatment, which was also statistically significant $(p=0.03)$ (Figure 3).

\section{Trail-Making Test A}

Comparison of trail-making test A-score changes between groups revealed there was deterioration in scores in patients of group VPA compared to patients of group LEV, which showed improvement. There was a significant difference between groups 3 months after treatment, with means of

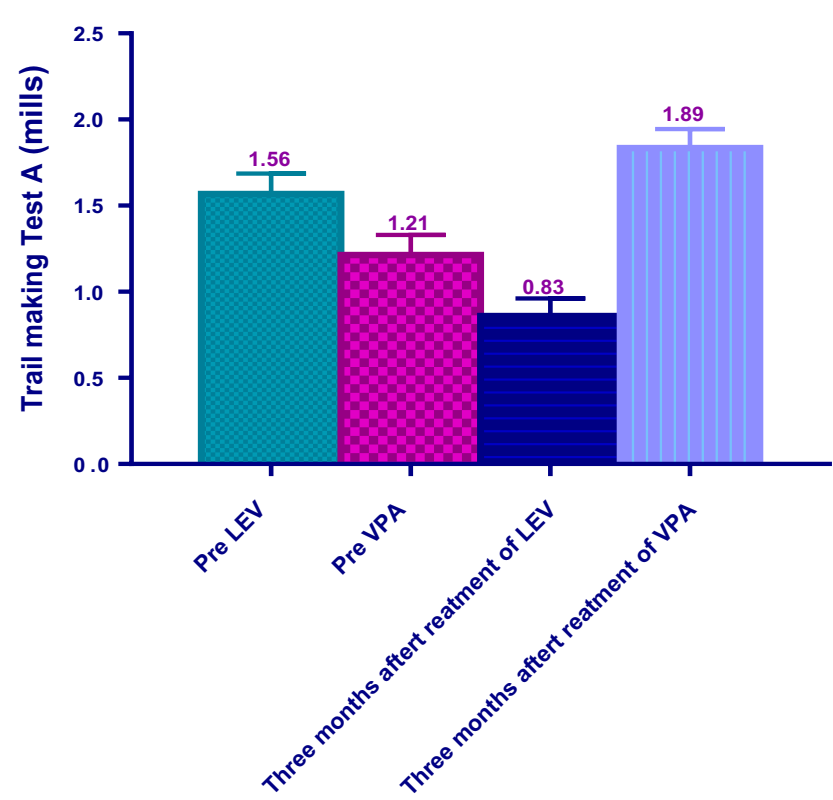

Figure 4 Effect of LEV group and VPA group on Trial making test A. Abbreviations: LEV, levetiracetam, VPA, sodium valproate.
$0.83 \pm 0.49$ for LEV and $1.89 \pm 0.62$ for VPA $(p<0.0001)$, and significant improvement was seen from $1.56 \pm 0.59$ at pretreatment to $0.83 \pm 0.49$ at 3 months after treatment in the LEV group $(p=0.0001)$. In the VPA group, scores deteriorated from $1.21 \pm 0.58$ at pretreatment to 1.89 \pm 0.62 at 3 months after treatment, which was also statistically significant ( $p=0.001)$ (Figure 4$)$.

\section{Trail-Making Test B}

Comparison of trail-making test B-score changes between groups revealed there was deterioration in scores in patients of group VPA compared to group LEV, which showed improvements. There was a significant difference between groups 3 months after treatment, where means were $1.63 \pm 0.69$ for LEV and $2.94 \pm 0.0 .84$ for VPA $(p<0.0001)$, and significant improvement from $2.45 \pm 0.96$ at pretreatment to $1.63 \pm 0.69$ at 3 months after treatment in the LEV group $(p=0.009)$. In the VPA group, the score deteriorated from $2.05 \pm 0.75$ at pretreatment to $2.94 \pm 0.0 .84$ at 3 months after treatment, which was also statistically significant $(p=0.003)$ (Figure 5).

\section{Wisconsin Card-Sorting Test}

Comparison of WCST score changes in between groups revealed there was deterioration in WCST scores in patients of group VPA compared to group LEV, which showed improvements in scores. At 3 months after treatment, means were $44.04 \pm 4.7$ for $\mathrm{LEV}$ and 25.08 \pm 5.33 for VPA $(p<0.0001)$, and significant improvement

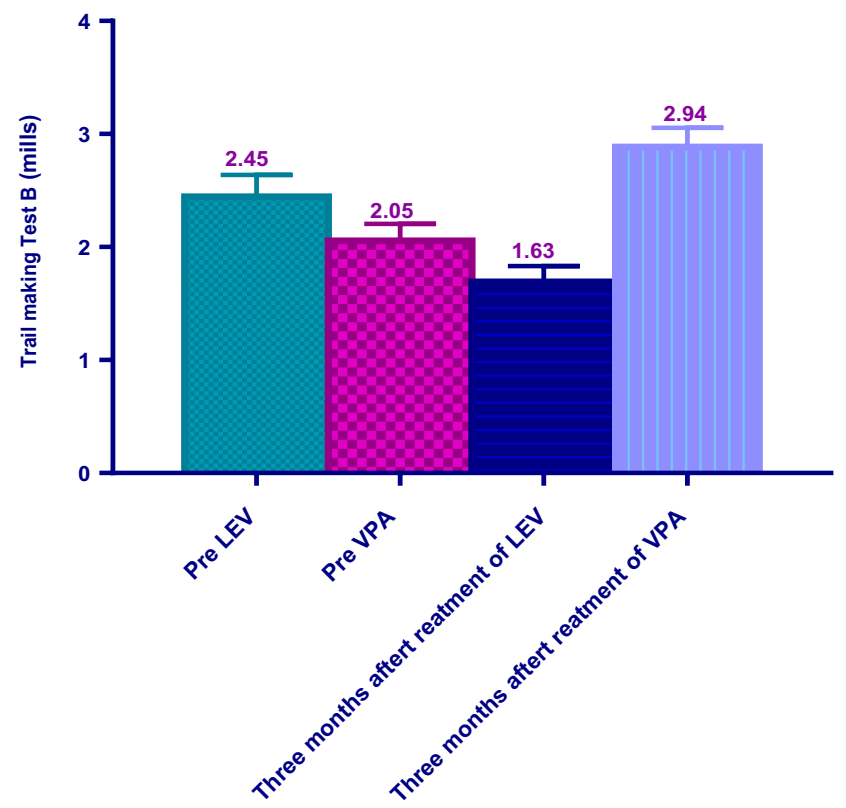

Figure 5 Effect of LEV group and VPA group on Trial making test B. Abbreviations: LEV, levetiracetam, VPA, sodium valproate. 
was seen from $32.68 \pm 5.8$ pretreatment to $44.04 \pm 4.7$ at 3 months after treatment in the LEV group $(p<0.0001)$. In the VPA group, scores deteriorated from $33.2 \pm 5.7$ at pretreatment to $25.08 \pm 5.33$ at 3 months after treatment, which was also statistically significant $(p<0.0001)$. There was a significant difference in nonperseveration errors between groups 3 months after treatment, with means of $6.88 \pm 2.7$ for $\mathrm{LEV}$ and $14.36 \pm 4.4$ for VPA $(p<0.0001)$. A significant improvement was seen from $12.76 \pm 3.8$ at pretreatment to $6.88 \pm 2.7$ at 3 months after treatment in the LEV group $(p<0.0001)$. In the VPA group, scores deteriorated from $11.76 \pm 4.2$ at pretreatment to $14.36 \pm 4.4$ at 3 months after treatment, which was not statistically significant $(p=0.09)$. There was a significant difference in perseveration errors between groups 3 months after treatment, with means of $9.08 \pm 3.5$
A
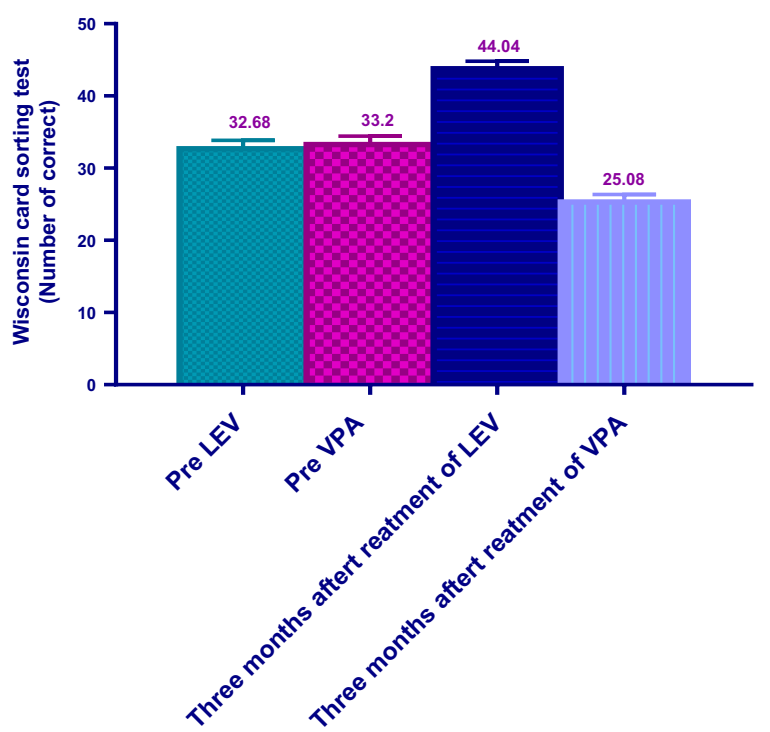

B

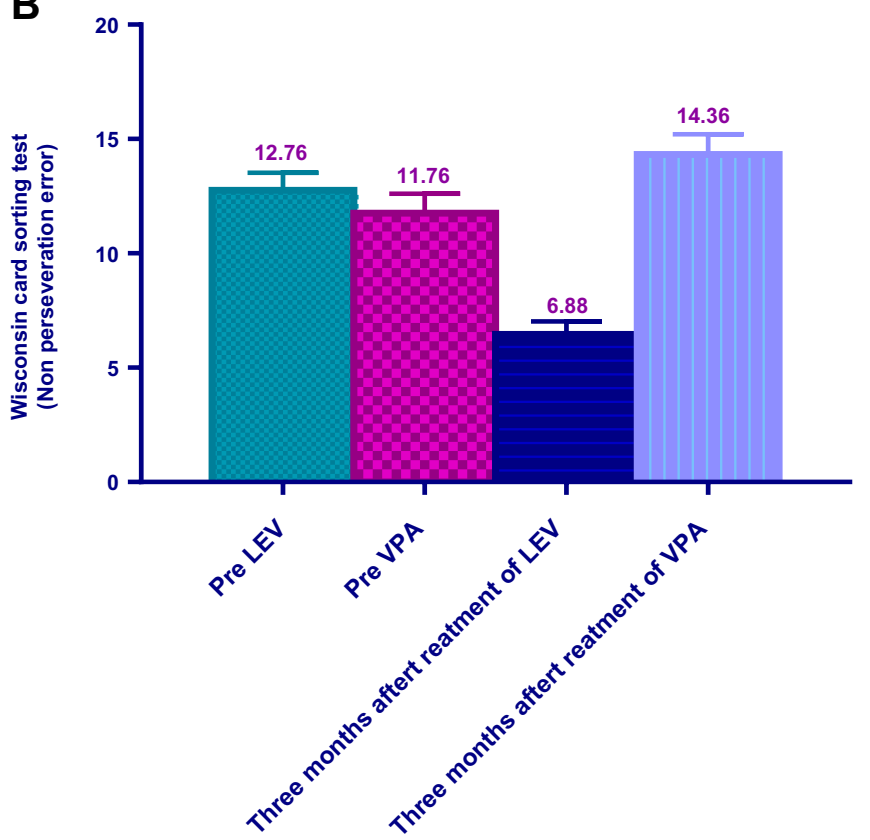

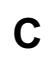
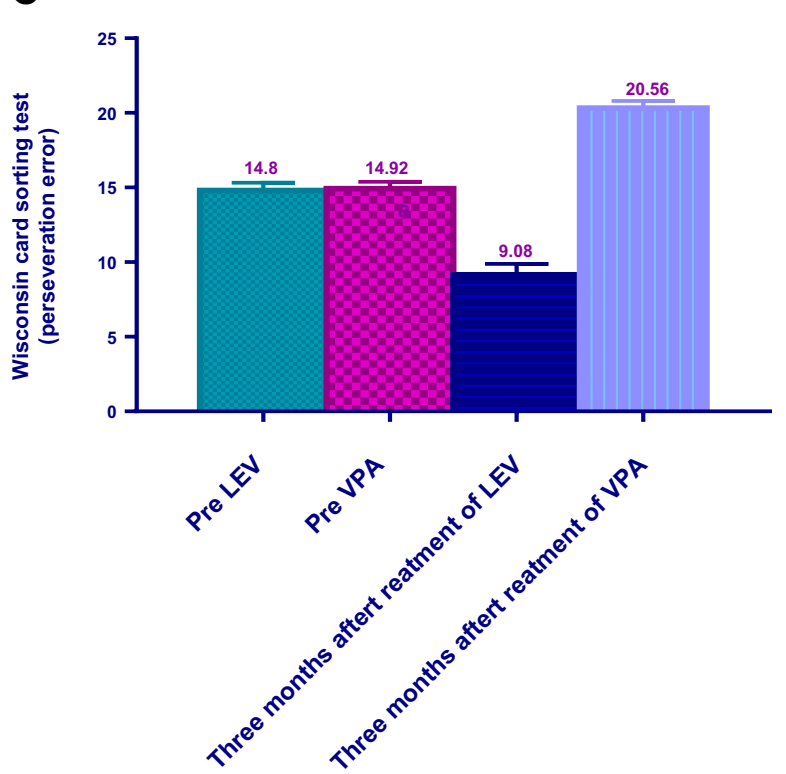

Figure 6 Effect of LEV group and VPA group on Wisconsin card sorting test (A) (Number of correct) (B) (Non-perseveration error) (C) (Perseveration error). Abbreviations: LEV, levetiracetam; VPA, sodium valproate. 
for LEV and 20.56 \pm 2.4 For VPA $(p<0.0001)$. Significant improvement was seen from $14.80 \pm 2.6$ at pretreatment to $9.08 \pm 3.5$ at 3 months after treatment in the LEV group $(p<0.0001)$. In the VPA group, scores deteriorated from $14.92 \pm 2.3$ at pretreatment to $20.56 \pm 2.4$ at 3 months after treatment, which was also statistically significant $(p<0.0001)$ (Figure 6).

\section{Discussion}

Epilepsy is generated by widespread and systematic mechanisms within the cerebral cortex, and memory and psychomotor functions may be impaired. Cognitive impairment can be due to the disease itself, as well as the antiseizure medications used in treatment. The effect of epilepsy itself on cognitive functions was not expected in our patients, as they were newly diagnosed cases. This study was designed to compare the effect of LEV to VPA on cognitive functions of patients with epilepsy when used as monotherapy. The authors of this study expected that LEV would have a good impact on cognitive functions compared to VPA.

General demographic features included in this analysis were age, sex, and educational level, and there were no statistically significant differences between the two groups treated with LEV and VPA. Better seizure-frequency reduction in patients treated with LEV and VPA as monotherapy was noted, in agreement with Ansa et al, who reported that VPA and LEV treatment caused undeniable reductions in seizure frequency before and after treatment. $^{15}$ Along the same lines, our results showed improvements in mental skill domains following LEV monotherapy. This is consistent with previous studies that have found LEV as adjunctive treatment can reduce the frequency of seizures and enhance cognitive function. ${ }^{16,17}$

The current results showed improvement in cognitive functions, including psychomotor speed, attention, mental flexibility, and executive function in the LEV group. This is in agreement with previous studies that have reported improvement in cognitive functions in patients treated with LEV as monotherapy. ${ }^{18,19}$ In the current study, it was found that there were highly significant improvements in attention and concentration measured by the WCST in the LEV group, in agreement with Noh et al, who found improvement in domains of cognition in patients treated with LEV as monotherapy. ${ }^{20}$ Furthermore, that a highly significant improvements in processing speed, mental flexibility, and executive functioning on trail-making tests
A and B in the LEV group compared to the VPA group were demonstrated, in agreement with previous studies $^{21,22}$ finding that both trail-making test A and reaction-time results showed significant differences with LEV treatment.

Similarly, previous reports have confirmed that there is no increase in reaction time and little evidence of attention impairment with new antiseizure medications compared to VPA. ${ }^{23,24}$ Possible mechanisms that might explain cognitive enhancement with LEV include the fact that LEVhas a specific stereoselective binding site in the central nervous system at SV2A and that LEV can reduce neuronal necrosis and maintain long-term potentiation in the hippocampus, which may also contribute to its effects on cognition. $^{25}$ It has been suggested that LEV can improve attention and memory, because this compound is the $\alpha$-ethyl analogue of the nootropic agent piracetam. Both belong to the pyrrolidine class, and these drugs might improve mental function, such as learning and memory, while protecting against seizures. ${ }^{26}$ However, it is rational to suppose that improved cognitive function with LEV is due to its effect on the metabolism of some frontal areas. ${ }^{27}$ Unfortunately, treatment with VPA caused an impairment in measured domains of cognitive performance. This is in agreement with a previous study, which reported that the choice reaction-time test showed an improvements in reaction time for some antiseizure medications and slowing for VPA. ${ }^{28}$

On the other hand, in the current study patients who were treated with VPAhad poor psychomotor skills and memory compared to those on LEV. Cavanna et al reported that VPA also impairs concentration, complex decision-making, and vasomotor function. ${ }^{29}$ It was concluded that antiseizure medications, ie, phenytoin, VP, and carbamazepine, together with other drugs used in combination, have an effect on vision, awareness, comprehension, cognitive integration, and memory. The impact was more with polytherapy than monotherapy. ${ }^{30}$ Also, it has been found that VPA is more likely to cause attentional dysfunction than ethosuximide in children with generalized absence seizures. ${ }^{31}$ In a previous study, it was noticed that in the elderly, VPA may occasionally cause cognitive impairment and that this may be reversible after VPA discontinuation. ${ }^{32}$ Recently, Khanna et al reported on cognitive impairment with VPA use in many parameters of cognition, whereas improvements in cognition were seen with LEV on the same parameters. $^{33}$ 


\section{Limitations and Conclusion}

The limitations of the present study were the limited sample size and limited follow-up. Longer follow-up would provide interesting information regarding the long-term effects of treatment, and may help in decision-making when choosing efficient drugs for patients. The findings from this study demonstrated obvious effects of antiseizure medications as monotherapy on neuropsychological measures of attention and memory, as the results of the current study established that the new-generation LEV can improve cognitive functions, in contrast to the older drugs VPA. In light of the current results, it can be concluded that using LEV a monotherapy in patients with epilepsy was effective in controlling seizures, with the additional benefit of improving cognitive functions.

\section{Disclosure}

The authors declare that there is no conflict of interest associated with this study.

\section{References}

1. Espinosa-Jovel C, Toledano R, Aledo-Serrano Á, García-Morales I, Gil-Nagel A. Epidemiological profile of epilepsy in low income populations. Seizure. 2018;56:67-72. doi:10.1016/j.seizure.2018.02. 002

2. Brodie MJ, Barry S, Bamagous GA, Norrie JD, Kwan P. Patterns of treatment response in newly diagnosed epilepsy. Neurology. 2012;78 (20):1548-1554. doi:10.1212/WNL.0b013e3182563b19

3. Kerr C, Nixon A, Angalakuditi M. The impact of epilepsy on children and adult patients' lives: development of a conceptual model from qualitative literature. Seizure. 2011;20(10):764-774. doi:10.1016/j.seizure.2011.07.007

4. Loring DW, Marino S, Meador KJ. Neuropsychological and behavioral effects of antiepilepsy drugs. Neuropsychol Rev. 2007;17:413-425. doi:10.1007/s11065-007-9043-9

5. Carpay JA, Aldenkamp AP. Complaints associated with the use of antiepileptic drugs: results from a community-based study. Seizure. 2005;14(3):198-206. doi:10.1016/j.seizure.2005.01.008

6. Kwan P, Arzimanoglou AT, Berg AT, et al. Definition of drug resistant epilepsy: consensus proposal by the ad hoc task force of the ILAE commission on therapeutic strategies. Epilepsia. 2010;51 (6):1069-1077. doi:10.1111/j.1528-1167.2009.02397.x

7. Helmstaedter C, Witt JA. Cognitive outcome of antiepileptic treatment with levetiracetam versus carbamazepine monotherapy: a non-interventional surveillance trial. Epilep Behav. 2010;18:74-80. doi:10.1016/j.yebeh.2010.02.011

8. Mulleners WM, McCrory DC, Linde M. Antiepileptics in migraine prophylaxis: an updated Cochrane review. Cephalalgia. 2015;35:51-62. doi:10.1177/0333102414534325

9. Lattanzi S, Trinka E, Del Giovane C, Nardone R, Silvestrini M, Brigo F. Antiepileptic drug monotherapy for epilepsy in the elderly: a systematic review and network meta-analysis. Epilepsia. 2019;60:2245-2254. doi:10.1111/epi.16366

10. Lattanzi S, Zaccara G, Giovannelli F, et al. Antiepileptic monotherapy in newly diagnosed focal epilepsy. A network meta-analysis. Acta Neurol Scand. 2019;139:33-41. doi:10.1111/ane.13025
11. Fisher RS, Cross JH, D'Souza C, et al. Instruction manual for the ILAE 2017 operational classification of seizure types. Epilepsia. 2017;58:531-542. doi:10.1111/epi.13671

12. Deary IJ, Liewald D, Nissan J. A free, easy-to-use, computer-based simple and four-choice reaction time programme: the Deary-Liewald reaction time task. Behav Res Methods. 2011;43:258-268. doi:10.3758/s13428-010-0024-1

13. Lezak MD, Howieson DB, Loring DW, Hannay HJ, Fischer JS. Neuropsychological Assessment. 4th ed. Oxford University Press; 2004.

14. Kongs SK, Thompson LL, Iverson GL, Heaton RK. Wisconsin Card Sorting Test - 64 Card Computerized Version. Odessa: Psychological Assessment Resources; 2000.

15. Ansa S, Anil Babu A, Abdurahiman P, Seethadevi B. Comparative study on efficacy and safety of monotherapy with levetiracetam and valproic acid in epileptic patients. Int J Curr Res. 2016;8: 39409-39414.

16. Labiner DM, Ettinger AB, Fakhoury TA, et al. Effects of lamotrigine compared with levetiracetam on anger, hostility, and total mood in patients with partial epilepsy. Epilepsia. 2009;50:434-442. doi:10.1111/j.1528-1167.2008.01792.x

17. Lee JJ, Song HS, Hwang YH, Lee HW, Suh CK, Park SP. Psychiatric symptoms and quality of life in patients with drug-refractory epilepsy receiving adjunctive levetiracetam therapy. $J$ Clin Neurol. 2011;7:128-136. doi:10.3988/jen.2011.7.3.128

18. Cho JR, Koo DL, Joo EY, et al. Effect of levetiracetam monotherapy on background EEG activity and cognition in drug-naïve epilepsy patients. Clini Neurophysiol. 2012;123:883-891. doi:10.1016/j. clinph.2011.09.012

19. Magalhães JC, Gongora M, Vicente R, et al. The influence of levetiracetam in cognitive performance in healthy individuals: neuropsychological, behavioral and electrophysiological approach. Clin Psychopharmacol Neurosci. 2015;13:83-93. doi:10.9758/cpn.2015.13.1.83

20. Noh HJ, Joo EY, Kim ST, et al. The relationship between hippocampal volume and cognition in patients with chronic primary insomnia. J Clin Neurol. 2012;8:130-138. doi:10.3988/jen.2012.8.2.130

21. Eddy C, Rickards H, Cavanna A. The cognitive impact of antiepileptic drugs. Ther Adv Neurol Disord. 2011;4:385-407. doi:10.1177/ 1756285611417920

22. Zhou B, Zhang Q, Tian L, Xiao J, Stefan H, Zhou D. Effects of levetiracetam as an add-on therapy on cognitive function and quality of life in patients with refractory partial seizures. Epilep Behav. 2008;12:305-310. doi:10.1016/j.yebeh.2007.10.003

23. Meador KJ, Loring DW, Hulihan JF, Kamin M, Karim R. Differential cognitive and behavioral effects of topiramate and valproate. Neurology. 2003;60:1483-1488. doi:10.1212/01.WNL.0000063308.22506.19

24. Sun W, Wang Y, Wang W, Wu X. Attention changes in epilepsy patients following 3-month topiramate or valproate treatment revealed by event-related potential. Int $J$ Psychophysiol. 2008;68:235-241. doi:10.1016/j.ijpsycho.2008.02.003

25. Rigo JM, Hans G, Nguyen L, et al. The anti-epileptic drug levetiracetam reverses the inhibition by negative allosteric modulators of neuronal GABA- and glycine-gated currents. $\mathrm{Br} J$ Pharmacol. 2002;136:659-672. doi:10.1038/sj.bjp.0704766

26. Genton P, Van Vleymen B. Piracetam and levetiracetam: close structural similarities but different pharmacological and clinical profiles. Epilep Disord. 2000;2:99-105.

27. Piazzini A, Chifari R, Canevini MP, Turner K, Fontana SP, Canger R. Levetiracetam: an improvement of attention and of oral fluency in patients with partial epilepsy. Epilepsy Res. 2006;68:181-188. doi:10.1016/j.eplepsyres.2005.10.006

28. Aldenkamp AP, Baker G, Mulder OG, et al. multicenter, randomized clinical study to evaluate the effect on cognitive function of topiramate compared with valproate as add-on therapy to carbamazepine in patients with partial-onset seizures. Epilepsia. 2000;41:1167-1178. doi:10.1111/j.1528-1157.2000.tb00322.x 
29. Cavanna AE, Ali F, Rickards HE, McCorry D. Behavioral and cognitive effects of anti-epileptic drugs. Discov Med. 2010;9:138-144.

30. Gupta PP, Gandhi A, Desai M. Effect of antiepileptic drugs on psychomotor functions and memory in epilepsy patients. J Young Pharm. 2017;9:357-361. doi:10.5530/jyp.2017.9.71

31. Glauser TA, Cnaan A, Shinnar S, et al. Ethosuximide, valproic acid, and lamotrigine in childhood absence epilepsy. $N$ Engl J Med. 2010;362:790-799. doi:10.1056/NEJMoa0902014
32. Armon C, Shin C, Miller P, et al. Reversible parkinsonism and cognitive impairment with chronic valproate use. Neurology. 1996;47:626-635. doi:10.1212/WNL.47.3.626

33. Khanna BS, Singh Y, Sharma KJ, et al. Comparative evaluation of levetiracetam and valproic acid as monotherapy on cognitive impairment in patients of epilepsy. Int $J$ Basic Clin Pharmacol. 2019;8:674-680. doi:10.18203/2319-2003.ijbcp20191098

\section{Publish your work in this journal}

Neuropsychiatric Disease and Treatment is an international, peerreviewed journal of clinical therapeutics and pharmacology focusing on concise rapid reporting of clinical or pre-clinical studies on a range of neuropsychiatric and neurological disorders. This journal is indexed on PubMed Central, the 'PsycINFO' database and CAS, and is the official journal of The International Neuropsychiatric Association (INA). The manuscript management system is completely online and includes a very quick and fair peer-review system, which is all easy to use. Visit http://www.dovepress.com/testimonials.php to read real quotes from published authors. 